\title{
Spatial and seasonal variability of medium- and high-frequency gravity waves in the lower atmosphere revealed by US radiosonde data
}

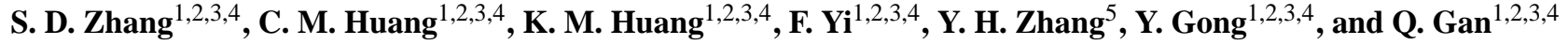 \\ ${ }^{1}$ School of Electronic Information, Wuhan University, Wuhan, Hubei, People's Republic of China \\ ${ }^{2}$ Key Laboratory of Geospace Environment and Geodesy, Ministry of Education, Wuhan, Hubei, People's Republic of China \\ ${ }^{3}$ State Observatory for Atmospheric Remote Sensing, Wuhan, People's Republic of China \\ ${ }^{4}$ State Key Laboratory of Information Engineering in Surveying, Mapping and Remote Sensing, Wuhan University, Wuhan, \\ People's Republic of China \\ ${ }^{5}$ College of Hydrometeorology, Nanjing University of Information Science and Technology, Nanjing, \\ People's Republic of China
}

Correspondence to: S. D. Zhang (zsd@whu.edu.cn)

Received: 6 April 2014 - Revised: 29 June 2014 - Accepted: 14 August 2014 - Published: 12 September 2014

\begin{abstract}
We extended the broad spectral method proposed by Zhang et al. (2013) for the extraction of medium- and high-frequency gravity waves (MHGWs). This method was applied to 11 years (1998-2008) of radiosonde data from 92 stations in the Northern Hemisphere to investigate latitudinal, continuous vertical and seasonal variability of MHGW parameters in the lower atmosphere $(2-25 \mathrm{~km})$. The latitudinal and vertical distributions of the wave energy density and horizontal momentum fluxes as well as their seasonal variations exhibit considerable consistency with those of inertial gravity waves. Despite the consistency, the MHGWs have much larger energy density, horizontal momentum fluxes and wave force, indicating the more important role of MHGWs in energy and momentum transportation and acceleration of the background. For the observed MHGWs, the vertical wavelengths are usually larger than $8 \mathrm{~km}$; the horizontal wavelengths peak in the middle troposphere at middle-high latitudes. These characteristics are obviously different from inertial gravity waves. The energy density and horizontal momentum fluxes have similar latitude-dependent seasonality: both of them are dominated by a semiannual variation at low latitudes and an annual variation at middle latitudes; however at high latitudes, they often exhibit more than two peaks per year in the troposphere. Compared with the inertial GWs, the derived intrinsic frequencies are more sensitive to the spatiotemporal variation of the buoyancy frequency, and at
\end{abstract}

all latitudinal regions they are higher in summer. The wavelengths have a weaker seasonal variation; an evident annual cycle can be observed only at middle latitudes.

Keywords. Meteorology and atmospheric dynamics (middle-atmosphere dynamics; waves and tides)

\section{Introduction}

The lower atmosphere is known as the main source region for atmospheric gravity waves (GWs). Due to the variety of GW sources (Fritts and Alexander, 2003, and references therein) and the complex spatiotemporal variability of the background environment in which GWs propagate, GWs in the realistic lower atmosphere should occur over a wide range of temporal scales, with periods varying from tens of minutes to several days. It is widely accepted that, among these many GW spectral components, GWs with higher frequency are more effective in carrying momentum and exert more significant impacts on background atmospheric dynamics than low-frequency GWs (Fritts and Vincent, 1987; Wang and Fritts, 1990; Nakamura et al., 1993).

Our knowledge of global lower-atmospheric GW climatology and latitudinal distribution benefit greatly from radiosonde and satellite observations (Pfenninger et al., 1999; Preusse et al., 2006; Wang and Geller, 2003; Ern et al., 
2004, 2011; Wang et al., 2005; Zhang and Yi, 2005, 2007; Venkat Ratnam et al., 2008; Debashis et al., 2009; Gong et al., 2008; Wang and Alexander, 2010; McDonald, et al., 2010; Zhang et al., 2010, 2012, 2013; Leena et al., 2012b; Hoffmann et al., 2013; Niranjan Kumar et al., 2012). Limited by the data processing method and observation techniques, most of the above studies concentrate on lower-atmospheric GWs with long horizontal wavelength, short vertical wavelength and low frequency, i.e., inertial GWs. A hodograph analysis method is the most widely applied method in the study of GWs from radiosonde observations. In this hodograph analysis, the ratio of the GW intrinsic frequency $\Omega$ to the Coriolis parameter $f$ is calculated from the ratio of the major to minor axes of an ellipse (Zhang and Yi, 2005, 2007) formed by GW horizontal wind disturbances. Since a toolarge ratio of $\Omega$ to $f$ will cause many uncertainties (Vincent and Alexander, 2000), a typical cut-off ratio of 10 is chosen in most studies (Vincent and Alexander, 2000). Therefore, the traditional hodograph analysis in fact can only be applied to study low-frequency GWs. Observational studies on lower-atmospheric medium- and high-frequency GWs (MHGWs) are mainly from only radiosonde at a tropical station (Leena et al., 2012b) and few radar observations at several limited sites (Dutta et al., 2009; Kuo et al., 2009, Leena et al., 2012b). Then, considering the long-term accumulations and extensive land distribution of radiosonde observations, in order to further understand the MHGWs in the lower atmosphere we need a feasible method to extract MHGW parameters from more radiosonde observations.

Besides the hodograph analysis, the ratio $\frac{\Omega}{f}$ as well as the GW intrinsic frequency $\Omega$ can also be derived from wave energy densities in two different expressions (Geller and Gong, 2010). One is in terms of the horizontal kinetic energy density $E_{\mathrm{Kh}}$ and the potential energy density $E_{\mathrm{P}}$, i.e.

$\frac{\Omega^{2}}{f^{2}}=\frac{E_{\mathrm{Kh}}+E_{\mathrm{P}}}{E_{\mathrm{Kh}}-E_{\mathrm{P}}}$.

The other one is from $E_{\mathrm{P}}$ and the vertical fluctuation energy density $E_{\mathrm{Kw}}$ :

$\frac{\Omega^{2}}{N^{2}}=\frac{E_{\mathrm{Kw}}}{E_{\mathrm{P}}}$.

According to the GW theory, these two expressions should be equivalent. However, by analyzing radiosonde observation data, Geller and Gong (2010) and Zhang et al. (2012) found that the wave intrinsic frequency derived from Eq. (2) was much larger than that from Eq. (1). Geller and Gong (2010) pointed out that this discrepancy is attributed to the $E_{\mathrm{Kh}}$ being sensitive to low-frequency GWs, while the $E_{\mathrm{Kw}}$ is more sensitive to high-frequency GWs. Therefore, the intrinsic frequencies derived from Eqs. (1) and (2) may stand for frequencies of GWs with lower- and higher-frequency components, respectively. Furthermore, Gong and Geller (2010) and Zhang et al. (2012) actually confirmed the existence of higher-frequency GWs - i.e., MHGWs - in the radiosonde observations.

Most recently, by using a least square fitting in the temporal domain, Leena et al. (2012b) studied the loweratmospheric high-frequency GWs at a tropical site from radiosonde and mesosphere-stratosphere-troposphere (MST) radar observations. However, this high-frequency GW observation is generally sparse and concentrated at low latitude. Also, Leena et al. (2012b) presented the fitted high-frequency GW parameters (for example, vertical and horizontal wavelengths) over two separate height ranges - i.e., 2-16 and 16$30 \mathrm{~km}$ - instead of the continuous vertical evolution of wave parameters. Zhang et al. (2012) proposed a broad spectral analysis method to study the continuous vertical variation of GW parameters in the lower atmosphere at midlatitudes. Afterwards, Zhang et al. (2013) presented the latitudinal and continuous vertical variability of inertial GW parameters in the Northern Hemisphere. But, until now, there are no radiosonde observation studies on continuous vertical variation of MHGW over a wide latitudinal region.

In this study, we extend the broad spectral method to the extraction of MHGWs. Here, the term "medium- and highfrequency GW" only means a GW with frequency "higher" than that of the inertial GW and "much higher" than the Coriolis parameter $f$. These MHGWs cannot be extracted from the traditional hodograph. Since many statistical analyses (Zhang et al., 2010, 2013) have indicated that the intrinsic frequencies of inertial GWs in the lower atmosphere are smaller than 3.5 times $f$, in this study we define the MHGWs as GWs with intrinsic frequencies larger than 4 times $f$. Furthermore, by applying the method to 11 years (1998-2008) of radiosonde observations over 92 United States stations in the Northern Hemisphere, we investigate the latitudinal, continuous vertical and seasonal variability of MHGW parameters from the troposphere up to the lower stratosphere $(2-25 \mathrm{~km})$. The data set used and the MHGW extraction method are introduced in the following section. The primary features of MHGWs are given in Sect. 3, in which the MHGW energy densities, intrinsic frequencies, wavelengths and the horizontal momentum fluxes and wave forces are analyzed in detail in Sects. 3.1, 3.2, 3.3 and 3.4, respectively. In the last section, we present a brief summary of our study.

\section{Data description and analysis approach}

The same data set as adopted by Zhang et al. (2013) is used in the present study. This data set consists of routine high-resolution radiosonde data in 1998-2008 from 92 northern hemispheric stations. These stations cover a longitudinal range of $\left[170.22^{\circ} \mathrm{W}, 171.38^{\circ} \mathrm{E}\right]$ and a latitudinal coverage of $\left[6.97^{\circ} \mathrm{N}, 71.30^{\circ} \mathrm{N}\right]$. These data were freely downloaded from the Stratospheric Processes and Their Role in Climate Data Center (http://www.sparc.sunysb.edu/). The stations at latitudes lower than $20^{\circ} \mathrm{N}$ are located mainly on Caribbean 
islands and western tropical Pacific islands; stations at latitudes $20-50^{\circ} \mathrm{N}$ are located on the United States mainland; and at higher than $50^{\circ} \mathrm{N}$, the stations are located mainly in Alaska. The detailed geographical locations and available data accumulations of these 92 stations can be found from Fig. 1 in Wang and Geller (2003) and Table 1 in Zhang et al. (2010). Wang and Geller (2003) presented the first study on GW energy density in the lower atmosphere by using 4 years (1998-2001) of data from these stations. After then, this data set or its subset was extensively utilized to study the latitudinal and seasonal variations of inertial GW parameters, for instance, wave energy density, wavelength, frequency, momentum flux, etc.

With respect to the detailed information of the data set used in this study - including available routine data accumulations, data quality and preprocessing - the readers are referred to Zhang et al. $(2010,2013)$. The preprocessed profiles - i.e., the pressure $(P)$, temperature $(T)$, ascent rate $(\mathrm{AR})$, zonal wind $(u)$ and meridional wind $(v)$ profiles - have an even height resolution of $50 \mathrm{~m}$ in the height range of $2-$ $25 \mathrm{~km}$.

Here, we introduce the proposed broad spectral analysis method for MHGW parameter extraction. It is supposed that the observed parameters $(X=[u, v, \mathrm{AR}, T, \rho, P])$ mainly consist of background $(\bar{X})$ and GW perturbation components $\left(X^{\prime}\right)$, i.e., $X=\bar{X}+X^{\prime}$. As suggested by Reeder et al. (1999) and Lane et al. (1999), the perturbation component of the ascent rate $\mathrm{AR}^{\prime}$ is taken to be the vertical velocity fluctuation $w^{\prime}$. Considering the exponential decrease of the mass density and pressure with height, their GW perturbations are normalized by the background density, which is calculated from the background pressure and temperature. Therefore in the following, $X=\left[u, v, \mathrm{AR}, T, \frac{\rho}{\bar{\rho}}, \frac{P}{\bar{\rho}}\right]$ and $X^{\prime}=\left[u^{\prime}, v^{\prime}, w^{\prime}, T^{\prime}, \frac{\rho^{\prime}}{\bar{\rho}}, \frac{P^{\prime}}{\bar{\rho}}\right]$. Firstly, we adopt a two-step processing method to remove the background components. The first step is removing the monthly average value as the majority of the background components from the raw data. In order to avoid the potential contamination of tides (Huang et al., 2009) on our GW analyses, the monthly average was performed separately according to two balloon launch local times, i.e., 08:00 and 20:00 LT. The monthly averaged profile can capture the primary background structure and potential low-frequency oscillations, for instance, tides. In our calculations, no systematic differences with statistical significance in the MHGW parameters between these two local times are found. Moreover, we have carried out many trial calculations by applying different average window widths - for instance, 11, 21 and 25 days - and found the average window width has only limited influences on the statistics of the MHGW parameters. Then, the residual profiles are composed primarily by GW fluctuations. In the second step, a polynomial fitting is taken to the residual profiles and removed as the minority of the background structure. In previous hodograph analyses (Zhang and Yi, 2005, 2007), a second-polynomial fitting was applied separately to the troposphere and lower stratosphere regions. In the present broad spectral method, with regard to the extreme values of temperature around the tropopause and zonal wind at the jet height, we need a higher-order polynomial fitting. We tried third-, fourth- and fifth-polynomial fittings and found the third-polynomial fitting to be enough to effectively capture the vertical variation in the background components; the third-polynomial fitting is adopted in the second step of background removing.

Subsequently, for the purpose of extracting MHGWs, we applied a fourth-order Butterworth filter to the residual components of the raw data. The applied filter has as flat a wavelength response as possible in the passband, and the filtered signal is suppressed to about $-6 \mathrm{~dB}$ at the cut-off wavelengths. In the previous studies (Zhang et al., 2012, 2013) on inertial gravity waves, which usually have smaller frequencies and vertical wavelengths (no larger than $10 \mathrm{~km}$ ), a high-pass filter with a cut-off wavelength of $10 \mathrm{~km}$ was applied. In the present study, on the other hand, we focus on the MHGWs, which might have higher frequencies and larger vertical wavelengths. We have carried out many trial calculations with different cut-off vertical wavelengths to preestimate the vertical wavelength. A quantitative comparison among these trial calculations is presented in the following context. The trial calculations demonstrate that in most cases the MHGWs have vertical wavelengths larger than $8 \mathrm{~km}$, and the statistical MHGW parameters, including the wave propagation parameters such as the wave intrinsic frequency and wavelengths, are insensitive to the adopted cut-off vertical wavelength. Therefore we apply here a low-pass Butterworth filter with a cut-off wavelength of $8 \mathrm{~km}$ to extract the MHGW components. Finally, in order to suppress the smallscale fluctuations and noise arising from measurement errors and variation of drag coefficients of the balloon, the filtered profile is smoothed by a Hanning window. We selected the smoothing kernel of the Hanning window as

$H(z)=\left\{\begin{array}{lc}\frac{1}{2}\left[1+\cos \left(\frac{\pi z}{\alpha}\right)\right] & -\alpha \leq z \leq \alpha \\ 0 & \text { elsewhere }\end{array}\right.$,

where the vertical half-width $\alpha$ is set to be $0.7 \mathrm{~km}$ with a root mean square (rms) width of about $250 \mathrm{~m}$ (Zhang et al., 2012). Then, the smoothed perturbation profile is taken as the broad spectral MHGW disturbances for further analysis.

The modification of cut-off wavelengths for the adopted filter has only limited influences on the derived MHGW parameters, even on the vertical wavelengths of the MHGWs. We have carried out several computational experiments with different cut-off wavelengths, for example, band-pass filters with cut-off wavelengths of 8 and $20 \mathrm{~km}, 8$ and $15 \mathrm{~km}, 5$ and $20 \mathrm{~km}$ and 5 and $15 \mathrm{~km}$. Here we present a comparison of the extracted GW perturbations by applying the above different cut-off wavelengths in the filtering process in Fig. 1. We can observe from Fig. 1 that perturbations filtered by different filters are rather close to each other, indicating the choice of cut-off wavelengths has only slight influences on the derived 

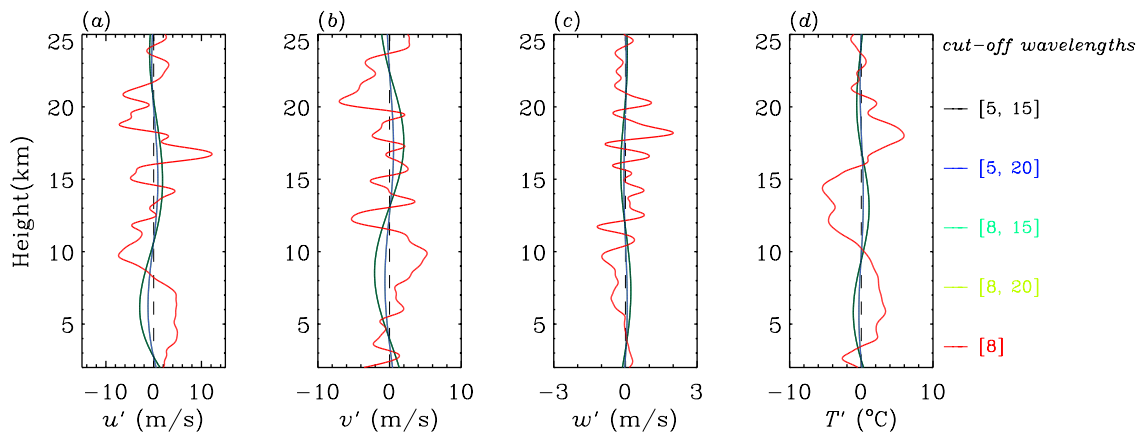

Figure 1. An example of gravity wave perturbations in zonal wind (a), meridional wind (b), vertical fluctuation (c) and temperature (d) profiles extracted from the radiosonde sounding launched at 08:00 LT on 20 January 1998 at a middle-latitude station, Miramar Nas (32.87 ${ }^{\circ}$, $\left.117.15^{\circ} \mathrm{W}\right), \mathrm{CA}$. Curves in red denote the perturbations extracted by low-pass filter with cut-off wavelength of $8 \mathrm{~km}$. Curves in the other colors denote the differences of the perturbations. These differences are obtained by subtracting the results extracted by the low-pass filter from those extracted by band-pass filters with different cut-off wavelengths, which are, respectively, 8 and $20 \mathrm{~km}, 8$ and $15 \mathrm{~km}, 5$ and $20 \mathrm{~km}$ and 5 and $15 \mathrm{~km}$.

MHGW perturbations as well as their vertical variations. In Fig. $1 \mathrm{GW}$ perturbations in different variables do not vary synchronously with height, which is related to the phase difference between different variables. Additionally, the dissipation process and broad spectral nature may also contribute to the departure of phase difference among difference GW perturbation variables from the linear GW polarization relation, which is based on monochromatic theory.

Having extracted the GW perturbations, the GW energy densities - i.e., zonal kinetic energy density $\left(E_{\mathrm{Ku}}\right)$, meridional kinetic energy density $\left(E_{\mathrm{Kv}}\right)$, vertical fluctuation energy density $\left(E_{\mathrm{Kw}}\right)$ and potential energy density $\left(E_{\mathrm{P}}\right)-$ can be easily derived from $E_{\mathrm{Ku}}=\frac{1}{2} \overline{u^{\prime 2}}, E_{\mathrm{Kv}}=\frac{1}{2} \overline{v^{\prime 2}}, E_{\mathrm{Kw}}=$ $\frac{1}{2} \overline{w^{\prime 2}}$ and $E_{\mathrm{P}}=\frac{1}{2} \frac{g^{2} T^{\prime 2}}{N^{2} \bar{T}^{2}}$, respectively, where $g$ is the gravitational acceleration and $\bar{T}$ is the background temperature. The overbars denote an average over a wavelength scale. In our calculation the average was realized by a low-pass filtering. As described above, since the vertical fluctuation energy density has the most sensitivity to high-frequency oscillation, we specify the wave intrinsic frequency from Eq. (2), i.e., from the $E_{\mathrm{P}}$ and $E_{\mathrm{Kw}}$. We want to note that it is the specification of wave intrinsic frequency from Eq. (2) rather than the filtering process that is the key step in analyzing the MHGW.

In our calculations, the other MHGW parameters are essentially based on the wave intrinsic frequency. Firstly, we calculate the vertical wave number $m$ from

$m=-\frac{\left(N^{2}-\Omega^{2}\right) w^{\prime} \bar{\rho}}{\Omega P^{\prime}}$,

where $P^{\prime}$ and $\bar{\rho}$ are, respectively, the pressure perturbation and background density; the height-dependent buoyancy frequency $N$ is derived from the background temperature. The positive and negative values of $m$ denote, respectively, the downward and upward energy propagation. So, the vertical wavelength is in fact derived from the wave intrinsic frequency instead of spectral analysis from the filtered perturbation profiles, and the cut-off vertical wavelength should have only limited effects on the derived MHGW vertical wavelength, which will be illustrated later. Subsequently, from the MHGW dispersion equation (Fritts and Alexander, 2003) we know that the zonal wave number $k$, meridional wave number $l$ and vertical wavenumber $m$ satisfy

$k_{h}^{2}=k^{2}+l^{2}=\frac{m^{2}\left(\Omega^{2}-f^{2}\right)}{\left(N^{2}-\Omega^{2}\right)}$.

Further, Zhang et al. (2012) deduced that the zonal and meridional wave numbers satisfy

$\frac{k^{2}}{l^{2}}=\frac{\overline{u^{\prime 2}} \Omega^{2}-\overline{v^{\prime 2}} f^{2}}{\overline{v^{\prime 2}} \Omega^{2}-\overline{u^{\prime 2}} f^{2}}$.

By combining Eqs. (4) and (5), the magnitudes of zonal and meridional wave numbers can be resolved. The signs of these horizontal wave numbers are conversely specified from the sign of the product of the vertical wave number and the mean horizontal momentum fluxes (Zhang et al., 2012).

To further illustrate the possible influences of the filter cutoff wavelengths on the derived MHGW parameters, we display the monthly averaged MHGW intrinsic frequency (in terms of $\frac{\Omega}{f}$ ) and vertical, zonal and meridional wavelengths derived by applying different cut-off wavelengths in Fig. 2. For $\frac{\Omega}{f}$, the monthly averaged values from different cut-off wavelengths are very close to each other. For wavelengths, even for the vertical wavelengths, the values and their vertical variations are very similar except those from the filter with cut-off wavelengths of 5 and $15 \mathrm{~km}$. Moreover, the estimated vertical wavelengths from different filters are all larger than $10 \mathrm{~km}$ at almost all heights, suggesting the larger vertical wavelength for MHGWs is the reliable physical result rather than a consequence from the filtering process. 

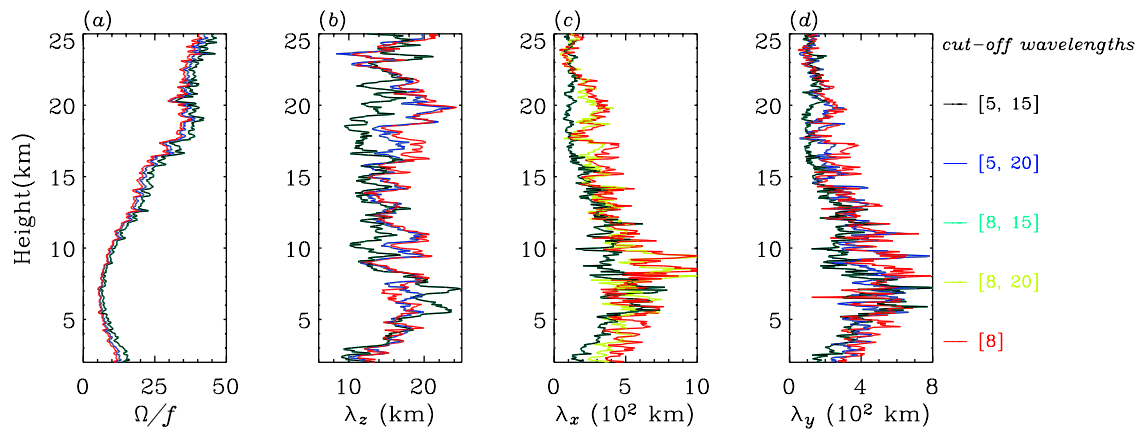

Figure 2. An example of the monthly averaged ratio of gravity wave intrinsic frequency to Coriolis parameter (a), vertical wavelength (b), zonal wavelength (c) and meridional wavelength (d) profiles at Miramar Nas (32.87 $\left.\mathrm{N}, 117.15^{\circ} \mathrm{W}\right)$, CA, in January 1998 . Curves in different colors denote the gravity wave parameters are derived by applying different filters, whose cut-off wavelengths are, respectively, 8 and $20 \mathrm{~km}$, 8 and $15 \mathrm{~km}, 5$ and $20 \mathrm{~km}$ and 5 and $15 \mathrm{~km}$.

We summarize the broad spectral method for MHGW here. Firstly, we removed the background components specified by a monthly average and a subsequent polynomial fitting, and then the residual components were filtered by a low-pass filter to eliminate inertial GW components, which usually have short wavelength. As presented above, the filtering process is important to extract fluctuations with longer vertical scales; however the derived MHGW parameters are not sensitive to the choice of the cut-off vertical wavelengths. Actually, the most important step in the broad spectral method is the specification of the intrinsic frequency from the vertical kinetic energy density. Subsequently, some of the other GW parameters are calculated based on the specified intrinsic frequency, which will be discussed in the following.

\section{Gravity waves}

\subsection{Gravity wave energy}

Figure 3 illustrates the 11-year (1998-2008) averaged spatial (latitudinal and vertical) variation of the MHGW energy densities, i.e., the potential energy density, zonal kinetic energy density, meridional kinetic energy density and vertical fluctuation energy density. Generally, the primary latitudinal and vertical variations of all energy densities are in good agreement with those of the inertial GWs reported by Zhang et al. (2013). For instance, the maximum energy densities in the troposphere occur at middle latitude, while the energy densities in the stratosphere are smaller and peak at low latitudes. More interestingly, in the lower stratosphere, in addition to the overall poleward decrease of wave energy densities, relatively weaker peaks in wave energy densities at middle latitude $\left(30-40^{\circ} \mathrm{N}\right)$ occur. These were also observed in the wave energy densities of inertial GWs (Zhang et al., 2010, 2013). The most prominent difference between the MHGWs and inertial GWs is in their magnitudes. The maxima of the potential, zonal, meridional and vertical fluctuation energy densities of the observed MHGWs are, respectively, 25.1, 15.0, 13.2 and $12.1 \times 10^{-2} \mathrm{~J} \mathrm{~m}^{-3}$, which are much larger than the corresponding energy density maxima (which are, respectively, 13.5, 6.7, 7.1 and $8.7 \times 10^{-2} \mathrm{~J} \mathrm{~m}^{-3}$ ) of inertial GWs (Zhang et al., 2013). The obviously larger densities emphasize the importance of MHGWs in the lower atmosphere.

To investigate the latitudinally dependent seasonality of MHGW energy, we calculated the monthly averaged total GW energy density $E_{\mathrm{T}}\left(E_{\mathrm{T}}=E_{\mathrm{P}}+E_{\mathrm{Ku}}+E_{\mathrm{Kv}}+E_{\mathrm{Kw}}\right)$ at (5$\left.15^{\circ} \mathrm{N}\right),\left(30-40^{\circ} \mathrm{N}\right)$ and $\left(65-75^{\circ} \mathrm{N}\right)$ to represent, respectively, the results at low, middle and high latitudes. Aiming at elucidating the seasonal variation of GW energy at different latitudes, here we discuss the possible primary wave sources rather than all sources at different latitudes. Figure 4a displays how at low latitudes the MHGW activity exhibits a semiannual oscillation, with the larger peaks in summer and weaker peaks in winter around $16 \mathrm{~km}$. The deep convection and strong westward wind shear above $20 \mathrm{~km}$ in summer and the occasionally occurring moderate eastward wind shear around $13 \mathrm{~km}$ in winter at low latitudes may be responsible for such a semiannual variation of the GW activity. Similar enhancement in tropical latitude of wave energy, especially in summer months, has also been found in inertial GWs (Zhang et al., 2012; Leena et al., 2012a). Leena et al. (2012a) suggested that although both the strong convection and wind shears in the westward phase contribute to the enhancement of GW activity, wind shear is mainly responsible. At middle latitudes (Fig. 4b), the MHGW energy density has an annual cycle, peaking at about $12 \mathrm{~km}$ in winter. Many studies (Zhang and Yi, 2005, 2007; Zhang et al., 2010, 2012,2013 ) have suggested that this prominent annual variation could be attributed to the intensive excitation of GWs by the strong vertical shear arising from the tropospheric jet in winter at middle latitudes. Then the annual variations of the zonal wind and the vertical shear of the zonal wind (with extremely large values in winter) lead to the annual variation in 

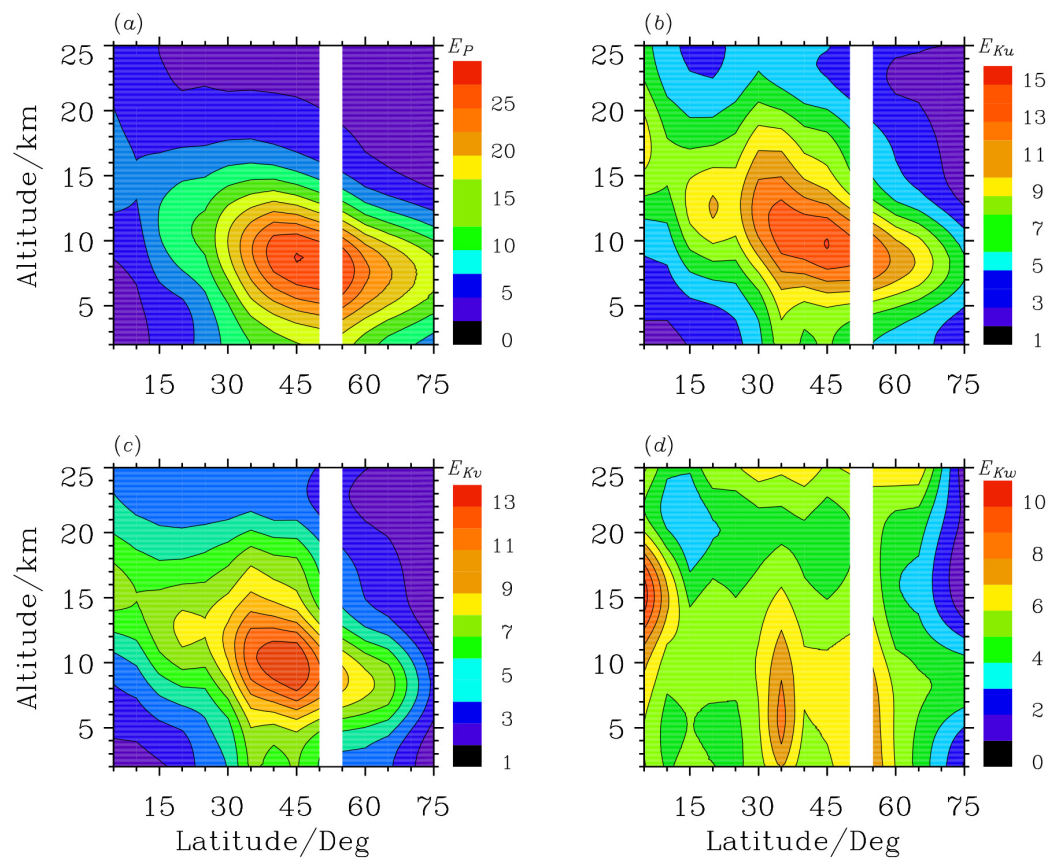

Figure 3. Latitudinal and vertical variations of 11-year averaged gravity wave potential energy density (a), zonal kinetic energy density (b), meridional kinetic energy density (c) and vertical fluctuation energy density (d). The zonal and meridional kinetic energy densities and potential energy density are in $\mathrm{J} \mathrm{m}^{-3}$; the vertical fluctuation energy is in $10^{-2} \mathrm{~J} \mathrm{~m}^{-3}$. The blanks denote no measurements.
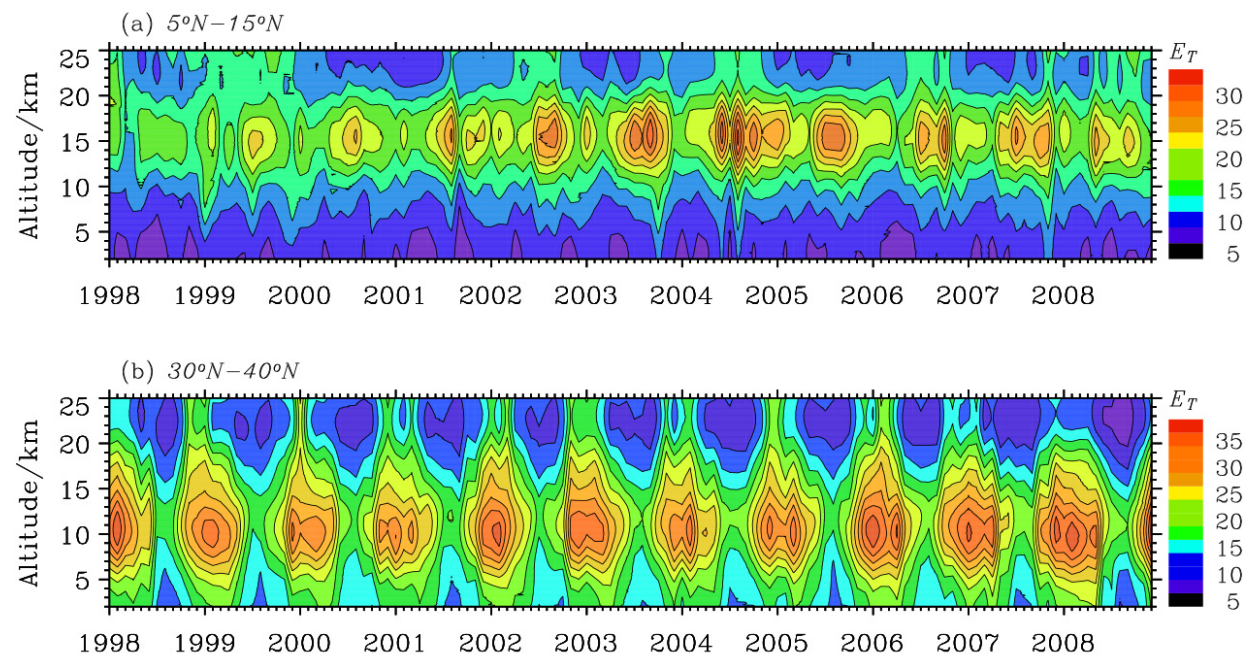

(c) $65^{\circ} \mathrm{N}-75^{\circ} \mathrm{N}$

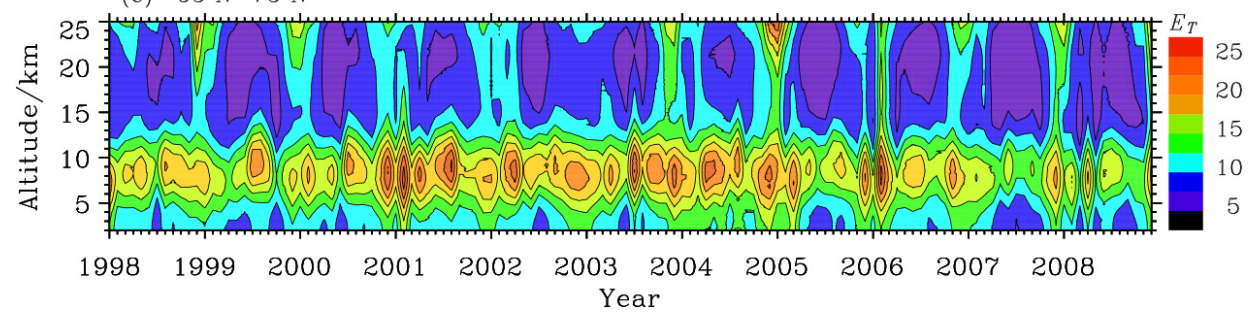

Figure 4. Monthly averaged total gravity wave energy densities (in $\mathrm{J} \mathrm{m}^{-3}$ ) at low (a), middle (b) and high (c) latitudes. 

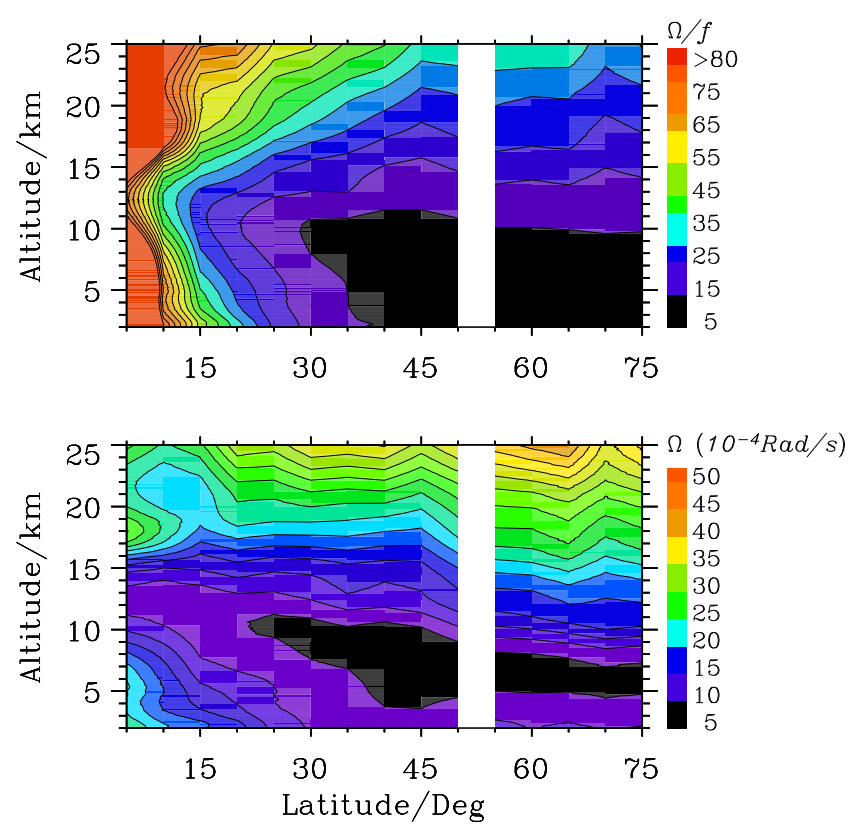

Figure 5. Latitudinal and vertical variations of the averaged ratio of $\frac{\Omega}{f}$ (upper panel) and intrinsic frequency $\Omega$ in $10^{-4} \mathrm{rad} \mathrm{s}^{-1}$ (lower panel) derived from the potential energy density and vertical fluctuation energy density. The blanks denote no measurements.

GW activity. The seasonal variation of MHGWs at high latitudes depends on height. Above $15 \mathrm{~km}$, the MHGW energy density exhibits an annual cycle, with stronger GW activity in winter, which might be attributed to the polar-night-jetinduced larger shear in winter. Below $15 \mathrm{~km}$, the seasonal variation of the MHGW energy density is complex: besides prominent peaks in winter and summer, large energy densities can also be observed in the other months in some years. A possible explanation for this complex seasonal variation is the lack of a strong seasonally dependent GW source as the deep convection at low latitudes and the strong jet at middle latitudes.

\subsection{Intrinsic frequency}

As discussed above, we deduced the wave intrinsic frequency from Eq. (2), which is the key processing step in extracting MHGW components. The ratio $\frac{\Omega}{f}$ and the wave intrinsic frequency of the MHGWs shown in Fig. 5 are much larger (at least 10 times larger) than those of the inertial GWs (Zhang et al., 2013). Also their latitudinal and vertical variations are different. The 11-year averaged ratio $\frac{\Omega}{f}$ is larger than 5 at all heights and latitudes, with the minimum ratio occurring at heights below $10 \mathrm{~km}$ for latitudes higher than $30^{\circ} \mathrm{N}$. At latitudes lower than $15^{\circ} \mathrm{N}$ the ratio is extremely large with a maximum value larger than 230 , and it decreases rapidly with the increase of latitude. However, the intrinsic frequency increases slightly with latitude, resulting from the increase of the Coriolis parameter $f$ with latitude. This is different from that of the inertial GWs, which show a rapid increase in intrinsic frequency with latitude. The most notable difference between the MHGW frequency and inertial GW frequency is their vertical variations. As given by Zhang et al. (2013), both the ratio $\frac{\Omega}{f}$ and intrinsic frequency for inertial GWs decrease with the increase of height, which is attributed to the Doppler shift of tropospheric wind. However for the MHGWs shown in Fig. 5, both the ratio $\frac{\Omega}{f}$ and intrinsic frequency increase significantly with height above $10 \mathrm{~km}$. Thus, $\frac{\Omega}{f}$ and $\Omega$ of the MHGWs are larger in the stratosphere rather than in the troposphere, as is the case for inertial GWs (Zhang et al., 2013). Additionally, the minimum intrinsic frequency (less than $10^{-3} \mathrm{rad} \mathrm{s}^{-1}$ ) appears in the middle troposphere, and the corresponding height descends with the latitude increase. At lower latitudes, the minimum intrinsic frequency height is $13 \mathrm{~km}$; it decreases to about $8 \mathrm{~km}$ at $75^{\circ} \mathrm{N}$.

Differences between the inertial GW and MHGW intrinsic frequencies can also be found in their seasonal variations. Zhang et al. (2013) reported that the inertial GW intrinsic frequency has only weak and sometimes irregular seasonal variation. In contrast, Fig. 6 illustrates that the MHGW intrinsic frequencies at different latitudes have evident seasonal variations. Generally, they have similar annual cycles, with a maximum in summer and minimum in winter. A possible explanation for the differences between the MHGW and inertial GW intrinsic frequencies may be that, since the MHGWs have higher frequencies compared with the inertial GWs, the MHGWs intrinsic frequencies are more sensitive to the variation of the buoyancy frequency and less sensitive to the background-wind-induced Doppler shifting. The MHGW dispersion equation (Fritts and Alexander, 2003) i.e., Eq. (4) - indicates that the intrinsic frequency $\Omega$ is positively correlated with the buoyancy frequency $N$. It is well known that the buoyancy frequency in the troposphere is much smaller than that in the lower stratosphere, and its minimum value occurs usually in the middle troposphere. Hereby, we can observe similar height variation in the intrinsic frequency of the MHGWs. However, the inertial GWs have lower frequencies and are easier to be Doppler-shifted to lower intrinsic frequencies by the tropospheric background wind; thus the intrinsic frequencies of the inertial GWs in the lower stratosphere are lower than in the troposphere. On the other hand, the buoyancy frequency usually has an annual variation, with the maximum and minimum values, respectively, in the lower stratosphere in summer and middle troposphere in winter (Zhang and Yi, 2005; Zhang et al., 2012). Interestingly, the intrinsic frequencies of MHGWs have a similar seasonal variation.

\subsection{Wavelengths and propagation directions}

In this subsection, we will investigate the averaged wavelength and propagation fractions, which are defined as the ratio of the number of GWs propagating in certain directions to the total GW number at each height. As shown in Fig. 7, all 

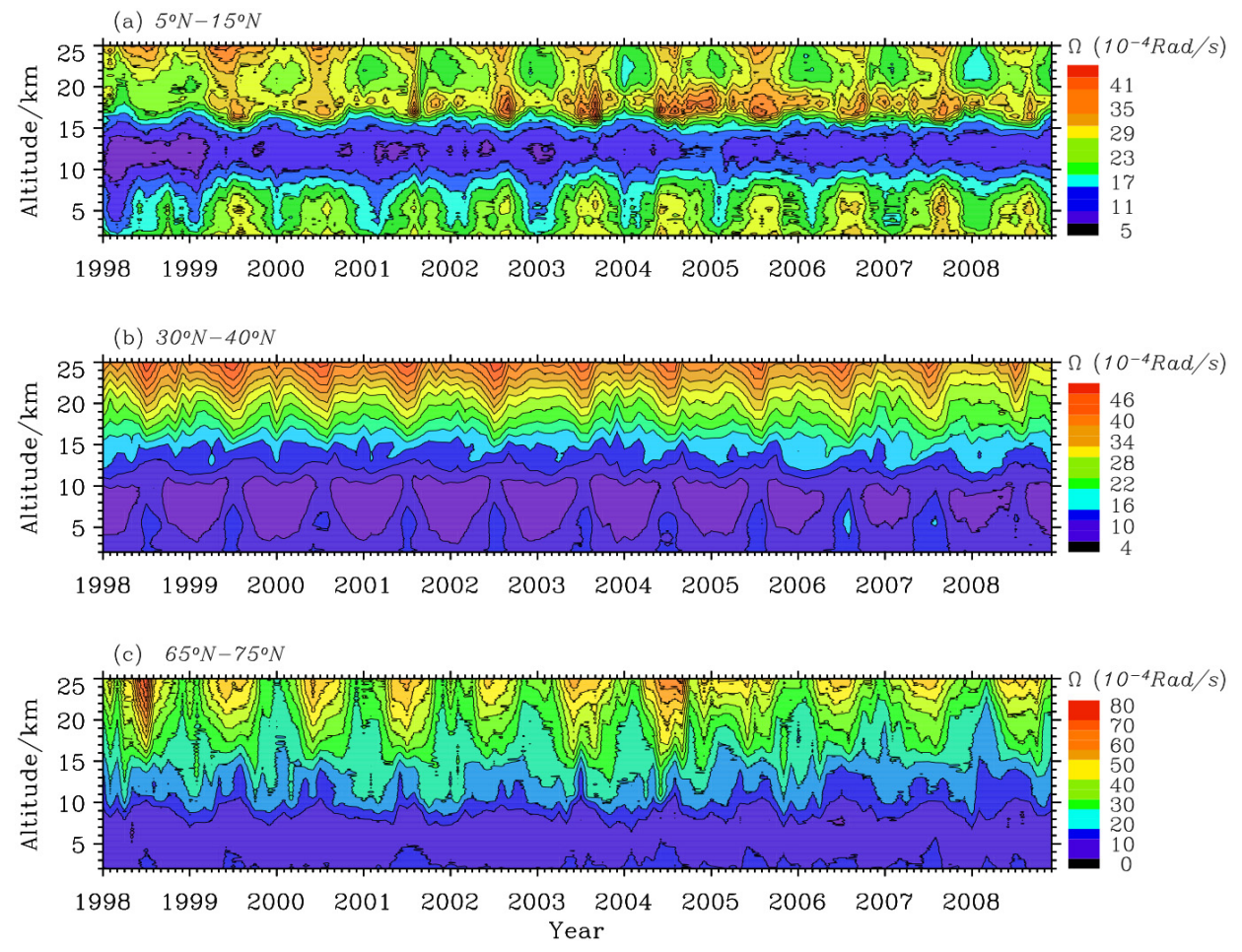

Figure 6. Monthly averaged intrinsic frequencies (in $10^{-4} \mathrm{rad} \mathrm{s}^{-1}$ ) of high-frequency gravity waves at low (a), middle (b) and high (c) latitudes.

wavelengths vary with latitude and height. Compared to the inertial GWs (Zhang et al., 2013), the vertical wavelengths of the MHGWs have much larger values (varying from 9 to $20 \mathrm{~km}$ ), and they increase with latitude. Their values at the lowest latitude are close to those reported by Leena et al. (2012b), who extracted the MHGW vertical wavelengths by using a least square fitting method on radiosonde data at a tropical site. By analyzing the satellite data, Ern et al. (2004) and Alexander et al. (2008) pointed out that waves below $25 \mathrm{~km}$ can have vertical wavelength longer than $10 \mathrm{~km}$. Niranjan Kumar et al. (2012) also found the stratospheric GWs can have vertical wavelength as long as $25 \mathrm{~km}$ from the Atmospheric Infrared Sounder (AIRS) and Microwave Limb Sounder (MLS).

There are two large vertical wavelength latitude-height regions. The first one is at the upper troposphere, with values larger than $16 \mathrm{~km}$ and height decreasing with the increasing latitude. A similar structure is found also in the minimum intrinsic frequency, the maximum upward propagation fraction and the maximum horizontal wavelength heights. This agreement among different GW parameters seems to imply that wave source characteristics significantly control the GW characters in the troposphere. Moreover, the downward tilt of the maximum vertical wavelength height with increasing latitude in the troposphere was also revealed in the inertial GWs by Zhang et al. (2013). Considering the troposphere is known as the main source region of GWs, the consistency between the MHGWs and inertial GWs in terms of the latitudinal and height variations of the vertical wavelength in the troposphere also suggests that they might be excited by the same primary sources.

The second large vertical wavelength region appears closely above the troposheric jet at middle and high latitudes, where the vertical wavelengths are larger than $17 \mathrm{~km}$. Two possible causes may be responsible for the longer vertical wavelength here: (1) the MHGWs above the tropospheric jet predominantly propagating against the jet. Their vertical wavelengths are enlarged by the jet since at the middle and high latitudes the tropospheric jet is usually strong. (2) The MHGWs is sensitive to and reversely proportional to the buoyancy frequency $N$, which decreases with latitudes above $17 \mathrm{~km}$.

The upward propagation fraction at heights below $8 \mathrm{~km}$ is around $50 \%$, demonstrating a possible source region here. In the upper troposphere, the upward-propagating fraction is larger than $60 \%$, and its latitudinal and vertical variations are similar to those of the tropospheric maximum vertical wavelength, except that the whole structure is slightly higher in the upward propagation fraction. Due to the tropospheric background wind absorption and/or reflection of some upwardpropagating GWs, the upward-propagating fraction in the lower stratosphere decreases to $51-57 \%$. 


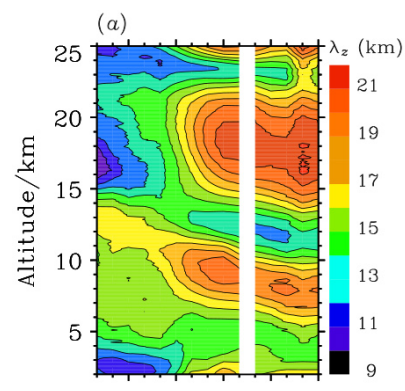

$1530 \quad 45 \quad 60 \quad 75$

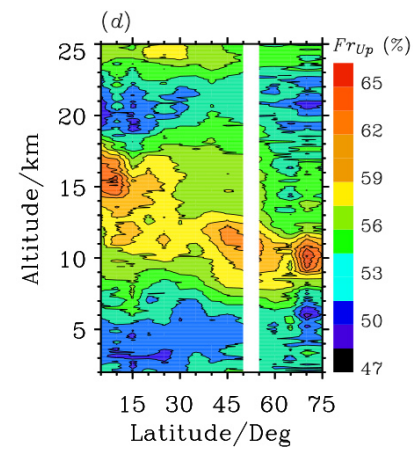

(b)

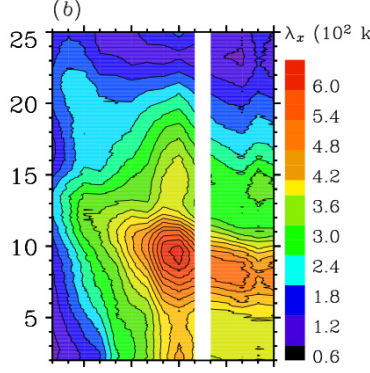

$1530 \quad 45 \quad 60 \quad 75$

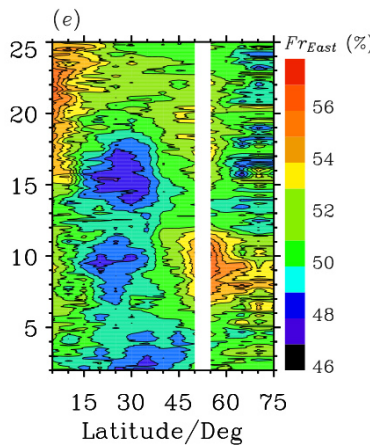

(c)

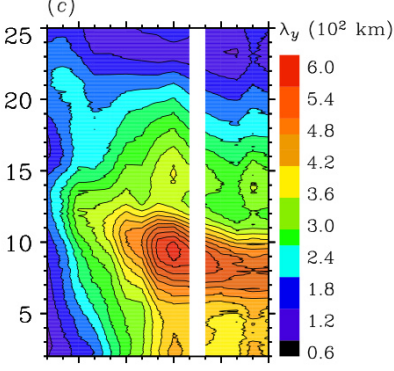

$1530 \quad 45 \quad 60 \quad 75$

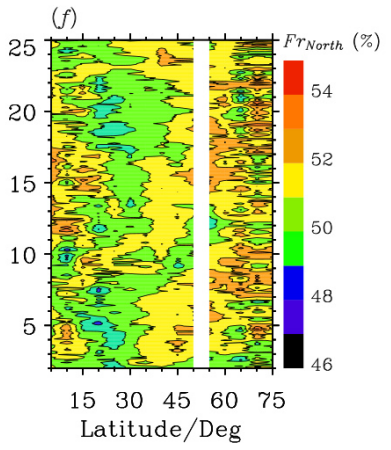

Figure 7. Latitudinal and vertical variations of averaged wavelengths (top) and propagation direction fractions (bottom). In the upper row the left (a), middle (b) and right (c) panels illustrate the vertical, zonal and meridional wavelengths, respectively. In the lower row, the left (d), middle (e) and right (f) panels illustrate, respectively, the fractions (in percentage) of upward, eastward and northward propagations. The blanks denote no measurements.

The 11-year averaged zonal wavelength shown in Fig. 7b has a similar value and spatial distribution to those of the meridional wavelength shown in Fig. 7c. Both of them vary in the range from 70 to $600 \mathrm{~km}$. The zonal and meridional wavelengths larger than $500 \mathrm{~km}$ are observed in the upper troposphere (around $10 \mathrm{~km}$ ) over the latitudes poleward from $30^{\circ} \mathrm{N}$, and the heights of the maxima vary with latitude, corresponding to those of the lowest intrinsic frequency. Over the tropical stations at latitudes lower than $15^{\circ} \mathrm{N}$, the horizontal wavelengths are much shorter, with values smaller than $180 \mathrm{~km}$. These latitudinal variations are different apparently from those of the inertial GWs (Zhang et al., 2013), for which the largest horizontal wavelengths occur at low latitudes. In the lower stratosphere, the horizontal wavelengths decrease with height due to the increase of intrinsic frequency, with maximum values no greater than $360 \mathrm{~km}$. The horizontal wavelengths in the stratosphere are generally shorter than those in the troposphere. The horizontal propagation of MHGWs is rather isotropic. Larger eastward propagation fraction occurs in the lower stratosphere over lowerlatitude stations and in the middle troposphere over middleand high-latitude stations.

The vertical and horizontal wavelengths have only weak annual variations. Here we present the composite annual variations of the vertical and zonal wavelengths at different latitudes from the 11-year data set in Fig. 8. The most prominent annual variations in both vertical and zonal wavelengths occur at middle latitudes $\left(30-40^{\circ} \mathrm{N}\right)$, where both the vertical and zonal wavelengths have larger values in winter (December, January and February) and smaller values in summer (June, July and August) at almost all observation heights. Only a slight annual variation of wavelengths can be observed at low and high latitudes. At low latitudes $\left(5-15^{\circ} \mathrm{N}\right)$, from June to November, the vertical wavelength is lager at almost all heights, except at $16 \mathrm{~km}$, where the vertical wavelength has its minimum value. The zonal wavelength is shorter from July to October. At high latitudes $\left(65-75^{\circ} \mathrm{N}\right)$, the MHGWs below $15 \mathrm{~km}$ have a shorter vertical wavelength in summer (June, July and August), while above $15 \mathrm{~km}$ the vertical wavelength is slightly larger in summer. The zonal wavelength at high latitudes is smaller in summer. Similar annual variation in the meridional wavelength (not presented) can also be observed.

\subsection{Momentum flux and wave force}

GWs can transport momentum from one atmospheric layer to another. When GWs dissipate, they deposit momentum into the local background atmosphere and thus exert a force on the background dynamic structure. Hence, the deduction of the magnitude and vertical gradient of the GW momentum flux is important in demonstrating the wave dissipation and the resulting force on the mean flow. Since we extracted the vertical fluctuation wind from the ascent rate of balloons, the 
(a) $5^{\circ} \mathrm{N}-15^{\circ} \mathrm{N}$

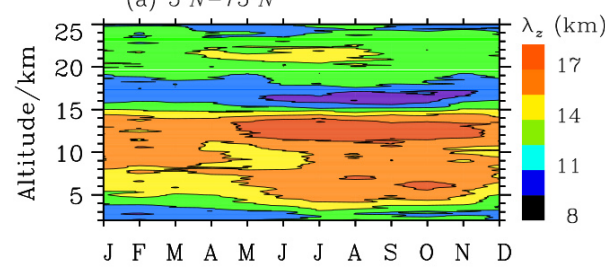

(c) $30^{\circ} \mathrm{N}-40^{\circ} \mathrm{N}$
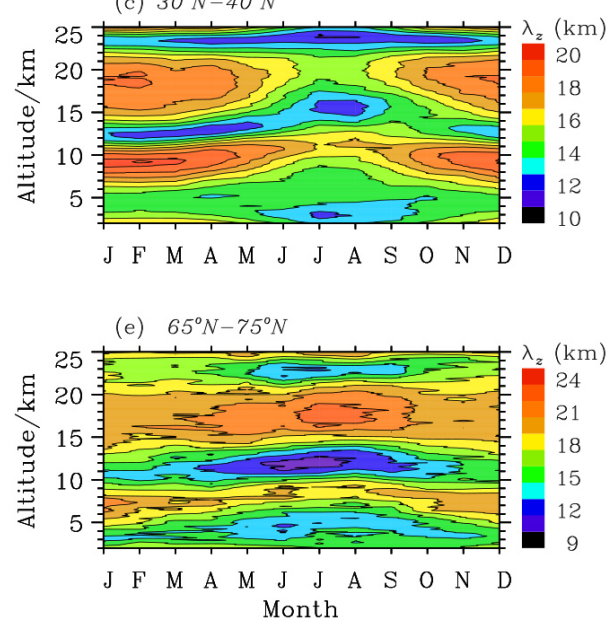

(b) $5^{\circ} \mathrm{N}-15^{\circ} \mathrm{N}$

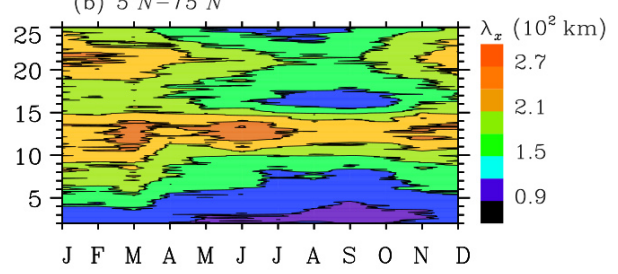

(d) $30^{\circ} \mathrm{N}-40^{\circ} \mathrm{N}$

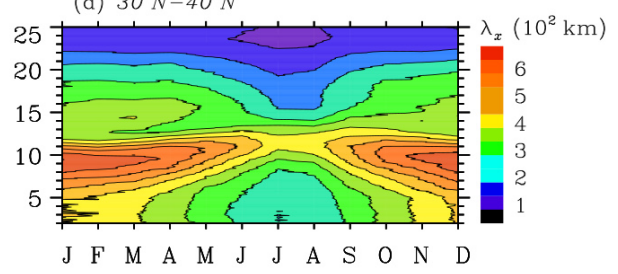

(f) $65^{\circ} \mathrm{N}-75^{\circ} \mathrm{N}$

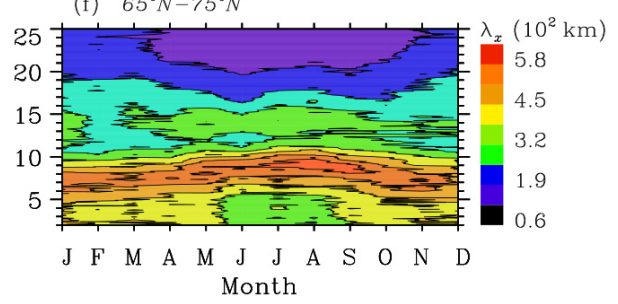

Figure 8. Annual variation of averaged vertical (left column) and zonal (right column) wavelengths at different latitudes. (a), (c) and (e) denote annual variations of averaged vertical wavelengths of high-frequency gravity waves at low, middle and high latitudes, respectively; (b), (d) and (f) denote annual variations of averaged zonal wavelengths of high-frequency gravity waves at low, middle and high latitudes, respectively.
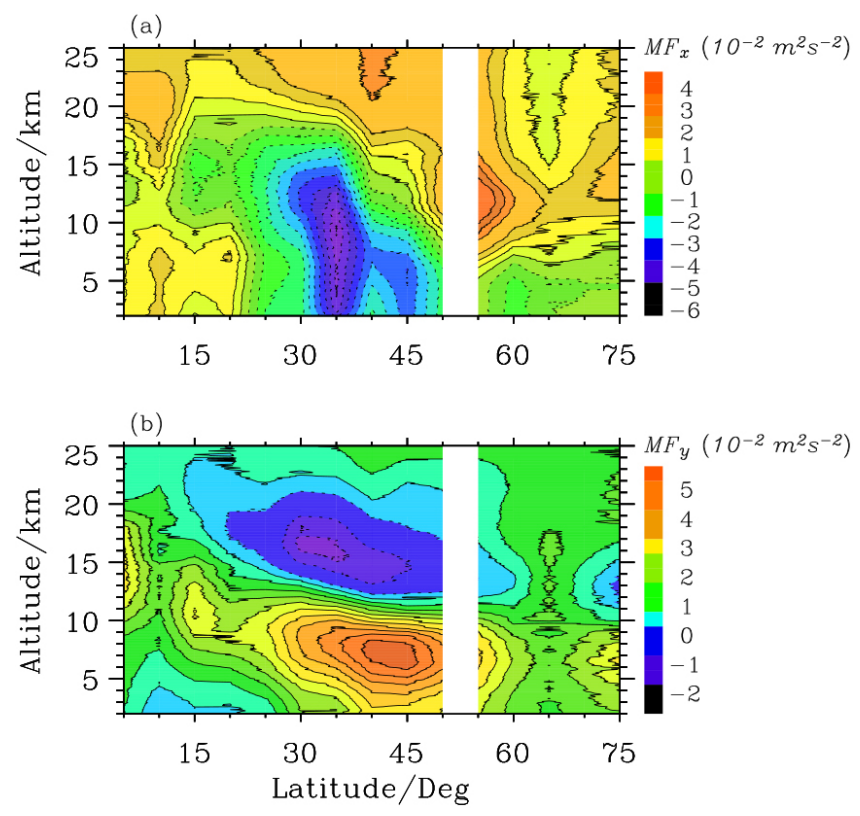

Figure 9. Latitudinal and vertical variations of averaged zonal (a) and meridional (b) momentum fluxes (in $10^{-2} \mathrm{~m}^{2} \mathrm{~s}^{-2}$ ). The blanks denote no measurements. zonal and meridional momentum fluxes can be directly calculated from $\mathrm{MF}_{x}=\overline{u^{\prime} w^{\prime}}$ and $\mathrm{MF}_{y}=\overline{v^{\prime} w^{\prime}}$, respectively.

We present the 11-year averaged zonal and meridional momentum fluxes in Fig. 9. The magnitudes of the momentum fluxes are in agreement with satellite observations (Alexander et al., 2008; Ern et al., 2011). For the zonal momentum flux, it varies from -6 to $+5 \mathrm{~m}^{2} \mathrm{~s}^{-2}$. The prominent negative flux occurs below $15 \mathrm{~km}$ at $20-50^{\circ} \mathrm{N}$, with negative maximum (in magnitude) flux appearing at $6 \mathrm{~km}, 35^{\circ} \mathrm{N}$. This strong negative flux region is below the strong tropospheric jet at the middle latitudes (Zhang et al., 2013), which seems to imply the link between the jet and the negative MHGW momentum flux below. Furthermore, a relatively weak negative flux region below $7 \mathrm{~km}$ at latitudes poleward from $55^{\circ} \mathrm{N}$ can be observed. Positive flux regions occur above the negative flux regions for $10-75^{\circ} \mathrm{N}$ and at all heights for the lowest latitudes $\left(5-10^{\circ} \mathrm{N}\right)$. Maxima occur around $12 \mathrm{~km}$ at $55^{\circ} \mathrm{N}$.

As for the averaged meridional momentum flux (shown in Fig. 9b), at latitudes lower than $15^{\circ} \mathrm{N}$ the momentum flux is positive everywhere, while at latitudes higher than $15^{\circ} \mathrm{N}$ there is a clear boundary between the positive and negative meridional momentum flux regions. This boundary tilts downward with the increase of latitude. For instance, at $15^{\circ} \mathrm{N}$ the boundary is at a height of $20 \mathrm{~km}$, while it decreases to about $12 \mathrm{~km}$ at latitudes higher than $60^{\circ} \mathrm{N}$. The 
negative and positive meridional momentum fluxes appear, respectively, above and below the boundary, i.e., in the lower stratosphere and troposphere. The positive and negative maximum meridional momentum fluxes are located at $7 \mathrm{~km}$ at $40^{\circ} \mathrm{N}$ and $17 \mathrm{~km}$ at $35^{\circ} \mathrm{N}$, respectively.

Figures 10 and 11 show, respectively, the monthly averaged zonal and meridional momentum fluxes at different latitudinal regions. At low latitudes $\left(5-15^{\circ} \mathrm{N}\right)$, both strong positive and negative zonal momentum fluxes concentrate mainly at heights of 10-20 km and show signs of possible semiannual variations. Eswaraiah et al. (2013) also reported strong horizontal momentum flux of MHGWs at heights of 11$16 \mathrm{~km}$ revealed by the very high frequency (VHF) radar observations at a low-latitude site, Gadanki $\left(13.5^{\circ} \mathrm{N}, 79.2^{\circ} \mathrm{E}\right)$, India. Strong negative zonal momentum fluxes occur usually in summer and sometimes at autumnal equinox; while the maximum positive zonal momentum flux occurs in winter, sometimes slightly weaker peaks of the positive momentum fluxes can be observed in summer. Similar behavior can also be observed in the meridional momentum flux, except that strong positive meridional momentum fluxes appear in vernal and autumnal equinoxes, and strong negative fluxes appear occasionally in the summer months.

The seasonal variations in both the zonal and meridional momentum fluxes at middle latitudes $\left(30-40^{\circ} \mathrm{N}\right)$ are dominated by an evident annual cycle. The positive and negative zonal momentum fluxes concentrate, respectively, in the lower stratosphere and troposphere, with positive and negative maxima occurring in winter and summer, respectively. The positive gradient of the zonal momentum flux indicates an eastward-decelerating MHGW force on the background zonal wind around the height of $10-20 \mathrm{~km}$. Conversely, the positive and negative meridional momentum fluxes appear mainly in the troposphere and lower stratosphere, respectively. Both the positive and negative fluxes reach their maximum values in winter. The negative gradient around $13 \mathrm{~km}$ in the meridional momentum flux indicates an acceleration effect of MHGWs on the background meridional wind. According to the GW theory, the sign of the meridional momentum flux $\mathrm{MF}_{y}$ is determined by $-\frac{l}{m}$. Figure 7 illustrates that GW propagation is nearly symmetric in the meridional direction around $13 \mathrm{~km}$; on the other hand, the upward propagation fraction decreases obviously above the jet. Therefore, the evident negative meridional momentum flux gradient around $13 \mathrm{~km}$ in winter may be closely related to the strong tropospheric jet in winter, which can dissipate or even absorb GWs propagating upward from below, in turn weakening the positive momentum flux and then leading to negative net meridional momentum flux.

At high latitudes $\left(65-75^{\circ} \mathrm{N}\right)$, the magnitudes of the momentum fluxes in the lower stratosphere are usually small, and the strong horizontal momentum fluxes occur mainly at heights below $15 \mathrm{~km}$. In each year, there are several positive peaks in both zonal and meridional components, most of them occurring in winter and summer. Occasionally, relatively smaller positive flux peaks can be observed in the other months.

Moreover, as shown in Fig. 9, although the peak value of the 11-year averaged momentum occurs at middle latitudes, both the zonal and meridional monthly averaged momentum fluxes peak at tropical latitudes, which is consistent with the latitudinal absolute momentum flux revealed by satellite observations (Alexander et al., 2008; Ern et al., 2011). It is noted that the vertical velocity fluctuation $w^{\prime}$ will have more high-frequency wave information than $u^{\prime}$ or $v^{\prime}$, which may introduce some uncertainty in deriving the momentum fluxes for MHGWs. But the reasonability of the derived results and the good consistency with previous satellite observations suggest this uncertainty does not invalidate the derived results significantly.

Due to momentum deposition, MHGWs will exert force on the background wind. The MHGW forces (shown in Fig. 12) are derived from $\left(F_{x}, F_{y}\right)=\left(-\frac{1}{\bar{\rho}} \frac{\partial \overline{\bar{\rho} u^{\prime} w^{\prime}}}{\partial z},-\frac{1}{\bar{\rho}} \frac{\partial \overline{\bar{\rho} v^{\prime} w^{\prime}}}{\partial z}\right)$, where $F_{x}$ and $F_{y}$ are the zonal and meridional wave forces, respectively. In the zonal direction, in the latitudinal range of $15-45^{\circ} \mathrm{N}$, the dominant wave force is westward, with a maximum value of $-1.5 \mathrm{~m} \mathrm{~s}^{-1}$ day $^{-1}$ (positive eastward) around the tropospheric jet height at $35^{\circ} \mathrm{N}$, suggesting the $\mathrm{GW}$-induced zonal force tends to decelerate the jet. The eastward force appears mainly in the tropical (equatorward from $15^{\circ} \mathrm{N}$ ) lower stratosphere (above $17 \mathrm{~km}$ ) and around $15 \mathrm{~km}$ at middle-high latitudes (poleward from $45^{\circ} \mathrm{N}$ ), with a maximum value of $1.1 \mathrm{~m} \mathrm{~s}^{-1} \mathrm{day}^{-1}$. As for the GW-induced meridional force, the positive (positive northward) region concentrates in a band around the tropopause heights with a thickness of $7 \mathrm{~km}$, indicating the northward acceleration effect of the MHGWs on the meridional wind around the tropopause. This positive force band tilts downward with the increase of latitude. Its bottom edge is located at $14 \mathrm{~km}$ at $5^{\circ} \mathrm{N}$ and descends to $7 \mathrm{~km}$ at $75^{\circ} \mathrm{N}$. The strongest northward acceleration of about $2.3 \mathrm{~m} \mathrm{~s}^{-1}$ day $^{-1}$ appears at $10 \mathrm{~km}$, $45^{\circ} \mathrm{N}$. Significant southward force regions occur closely above and below the northward force region, with a maximum deceleration of about $-1.0 \mathrm{~m} \mathrm{~s}^{-1} \mathrm{day}^{-1}$ at $17 \mathrm{~km}$, $45^{\circ} \mathrm{N}$. The vertical variation of the meridional force demonstrates that the MHGWs could produce a negative vertical shear in the background meridional wind around the tropopause.

Generally, the calculated latitudinal and vertical variations of the mean momentum fluxes and wave forces are rather similar to those of the inertial GWs as presented by Zhang et al. (2013), but the magnitudes of the momentum fluxes and wave forces of the presented MHGWs are much larger, at least 2 times those of the inertial GWs. This indicates that the GWs with high frequencies play a more dominant role in the momentum transportation and acceleration of background wind. For heat fluxes, we can draw similar conclusions based on an analysis of heat fluxes (not presented) associated with inertial GWs and MHGWs. 

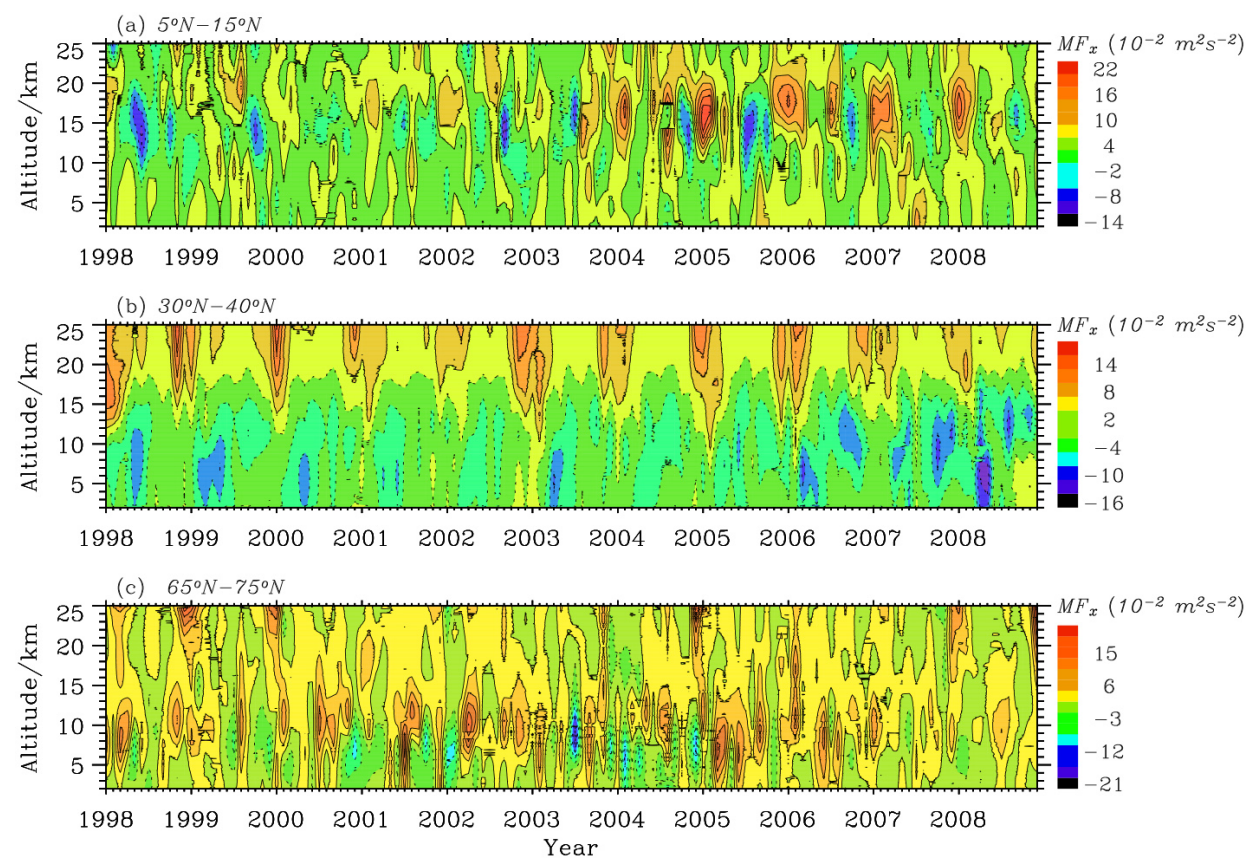

Figure 10. Monthly averaged zonal momentum fluxes (in $10^{-2} \mathrm{~m}^{2} \mathrm{~s}^{-2}$ ) at low (a), middle (b) and high (c) latitudes.
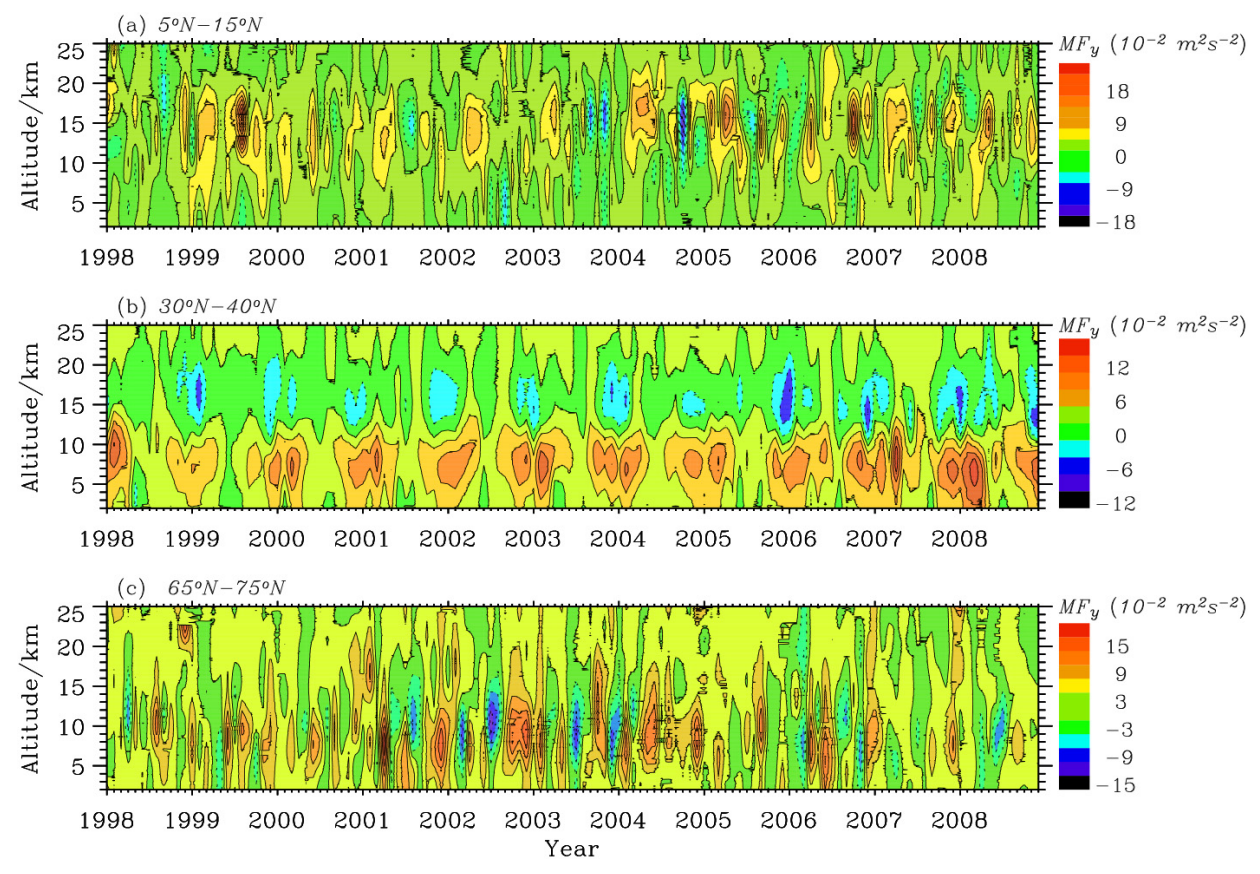

Figure 11. Monthly averaged meridional momentum fluxes (in $10^{-2} \mathrm{~m}^{2} \mathrm{~s}^{-2}$ ) at low (a), middle (b) and high (c) latitudes.

\section{Summary and remarks}

Zhang et al. (2012) proposed a broad spectral method to extract the continuous vertical variation of parameters for GWs with low frequencies, i.e., inertial GWs from radiosonde data. Here, we proposed a modified broad spectral method to extract GWs with higher frequencies from the same data set as adopted in Zhang et al. (2013). To our knowledge, it is the first presentation of latitudinal and continuous vertical variability of MHGW parameters from radiosonde data.

Generally, the primary latitudinal and vertical distribution of MHGW energy density, momentum flux and waveinduced force exhibit considerable consistency with those of the inertial GWs (Wang et al., 2005; Zhang et al., 2010; 

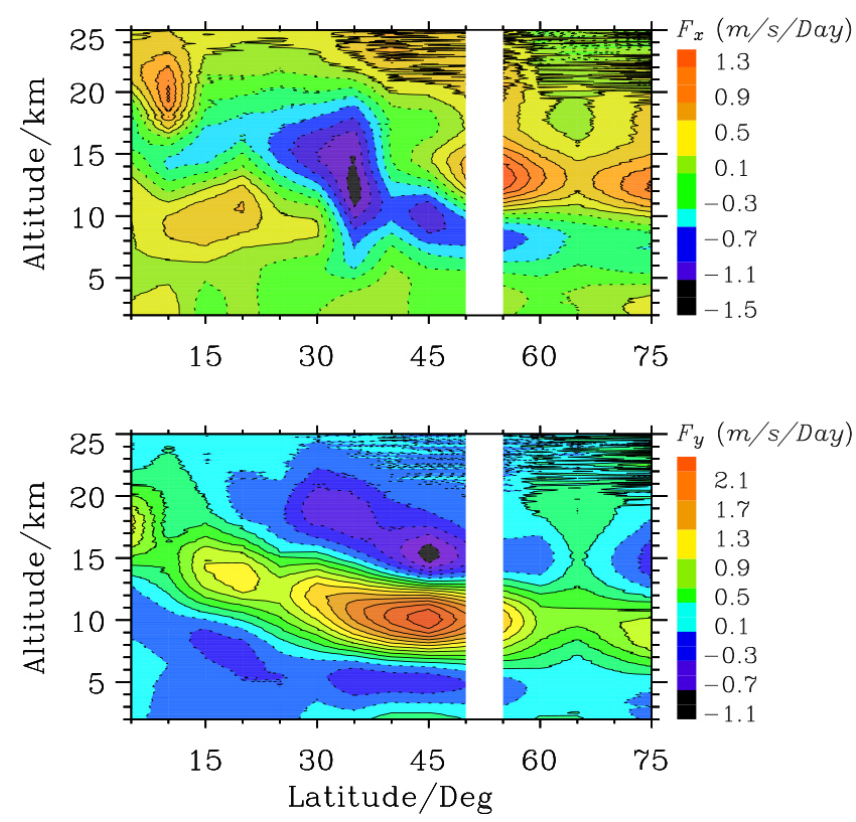

Figure 12. Latitudinal and vertical variations of averaged highfrequency-gravity-wave-induced zonal (upper panel) and meridional (lower panel) forces (in $\mathrm{m} \mathrm{s}^{-1} \mathrm{day}^{-1}$ ). The blanks denote no measurements.

Zhang et al., 2013), suggesting that the MHGWs and inertial GWs may be excited by similar primary sources. Despite considerable consistencies in spatial distribution, the magnitudes of wave energy densities, horizontal momentum fluxes, and wave force for MHGWs are about 2 times larger than those of inertial GWs, indicating that the MHGW plays a more dominant role in energy and momentum transportation as well as force on the background atmosphere.

Both the spatial distributions and magnitudes of the intrinsic frequency and wavelengths of MHGWs are evidently different from those of inertial GWs. For the presented MHGWs, the ratios of intrinsic frequency to the Coriolis parameter are generally larger than 10 , which is much larger than for inertial GWs. The ratio can reach a maximum value larger than 200 and decreases rapidly with increasing latitude. Although the intrinsic frequency has only slight vertical variation, both the ratio $\frac{\Omega}{f}$ and $\Omega$ increase with height above the middle troposphere, which is different from the decrease with height in intrinsic frequency for inertial GWs.

The vertical wavelength of the MHGWs varies from 9 to $20 \mathrm{~km}$, which is several times larger than that of inertial GWs. More interestingly, except for the large vertical wavelength occurring in the middle troposphere at almost all latitudes, which was also revealed in inertial GWs, much larger vertical wavelengths can be observed around $20 \mathrm{~km}$ at the middlehigh latitudes, which may be attributed to the Doppler shifting of the tropospheric jet and the decrease of $N$ with latitude. Different features between the MHGWs and inertial GWs can also be observed in the horizontal wavelengths.
Both the maximum zonal and meridional wavelengths occur in the middle troposphere over middle-high latitudes rather than over low latitudes as for inertial GWs.

The MHGW energy density and horizontal momentum fluxes have evident seasonal variations. At low latitudes (5$15^{\circ} \mathrm{N}$ ), the total wave energy density and horizontal momentum flux exhibit semiannual variations. The total energy density peaks in winter and summer, and, due to strong convection in summer, the summer peak is larger than the winter one. The positive zonal momentum flux is usually larger in winter and summer; the positive meridional momentum flux is higher in vernal and autumnal equinoxes. At middle latitudes, all these wave parameters have clear annual cycles, which is likely linked with the strong seasonal variation of the tropospheric zonal wind. The total wave energy density and the meridional momentum flux peak in winter. The zonal momentum flux in the troposphere reaches its minimum in summer, while in the lower stratosphere it has its maximum in winter. At high latitudes, the MHGW seasonal variation is complex. In the lower stratosphere, the wave energy density and horizontal momentum are dominated by an annual variation and peak in winter. In the troposphere, both the wave energy density and horizontal momentum flux are usually larger in winter, but they often have several peaks per year.

The derived intrinsic frequencies of the MHGWs at all latitudinal regions have an obvious annual cycle, with higher intrinsic frequency in summer. Compared with the other MHGW parameters, the wavelengths have weaker seasonal variation. An evident annual cycle can be observed only at middle latitudes, where both the vertical and horizontal wavelengths are larger in winter and smaller in summer.

Finally, we would like to emphasize that, since GWs play an important role in driving atmospheric dynamics at different scales, the observational constraints for the GWs are essential in furthering our understanding of atmospheric dynamics and developing atmospheric circulation models. Although it is known that MHGWs have strong impact in the upper atmosphere, most previous lower-atmosphere observations have concentrated on inertial GWs. The loweratmospheric MHGW observations are rare, especially in a wide geographical coverage. We hope this work can provide an important insight into MHGW sources and has potential contributions to the GW effects in the upper atmosphere.

Acknowledgements. This work was jointly supported by the National Basic Research Program of China (grant 2012CB825605), the National Natural Science Foundation of China (through grants 41221003, 41374155 and 41174126), the Specialized Fund for Comprehensive Study and Evaluation of the Polar Environment (grant CHINARE2014-02-03) and the Open Programs of the State Key Laboratory of Space Weather.

Topical Editor V. Kotroni thanks M. Geller and two anonymous referees for their help in evaluating this paper. 


\section{References}

Alexander, M. J., Gille, J., Cavanaugh, C., Coffey, M., Craig, C., Eden, T., Francis, G., Halvorson, C., Hannigan, J., Khosravi, R., Kinnison, D., Lee, H., Massie, S., Nardi, B., Barnett, J. Hepplewhite, C., Lambert, A., and Dean, V.: Global estimates of gravity wave momentum flux from High Resolution Dynamics Limb Sounder observations, J. Geophys. Res., 113, D15S18, doi:10.1029/2007JD008807, 2008.

Debashis, N., Venkat Ratnam, M., Jagannadha Rao, V. V. M., Krishna Murthy, B. V., and Vijaya Bhaskara Rao, S.: Gravity wave characteristics observed over a tropical station using highresolution GPS radiosonde soundings, J. Geophys. Res., 114, D06117, doi:10.1029/2008JD011056, 2009.

Dutta, G., Ajay Kumar, M. C., Vinay Kumar, P., Venkat Ratnam, M., Chandrashekar, M., Shibagaki, Y., Salauddin, M., and Basha, H. A.: Characteristics of high-frequency gravity waves generated by tropical deep convection: Case studies, J. Geophys. Res., 114, D18109, doi:10.1029/2008JD011332, 2009.

Ern, M., Preusse, P., Alexander, M. J., and Warner, C. D.: Absolute values of gravity wave momentum flux derived from satellite data, J. Geophys. Res., 109, D20103, doi:10.1029/2004JD004752, 2004.

Ern, M., Preusse, P., Gille, J. C., Hepplewhite, C. L., Mlynczak, M. G., Russell III, J. M., and Riese, M.: Implications for atmospheric dynamics derived from global observations of gravity wave momentum flux in stratosphere and mesosphere, J. Geophys. Res., 116, D19107, doi:10.1029/2011JD015821, 2011.

Eswaraiah, S., Venkat Ratnam, M., Krishna Murthy, B. V., Guharay, A. and Vijaya Bhaskara Rao, S.: Short period gravity wave momentum fluxes observed in the tropical troposphere, stratosphere and mesosphere, J. Atmos. Sol.-Terr. Phys., 105-106, 1-7, 2013.

Fritts, D. C. and Alexander, M. J.: Gravity wave dynamics and effects in the middle atmosphere, Rev. Geophys., 41, 1003, doi:10.1029/2001RG000106, 2003.

Fritts, D. C. and Vincent, R. A.: Mesospheric momentum flux studies at Adelaide, Australia: Observations and a gravity wave tidal interaction model, J. Atmos. Sci., 44, 605-619, 1987.

Geller, M. A. and Gong, J.: Gravity wave kinetic, potential, and vertical fluctuation energies as indicators of different frequency gravity waves, J. Geophys. Res., 115, D11111, doi:10.1029/2009JD012266, 2010.

Gong, J. and Geller, M. A.: Vertical fluctuation energy in United States high vertical resolution radiosonde data as an indicator of convective gravity wave sources, J. Geophys. Res., 115, D11110, doi:10.1029/2009JD012265, 2010.

Gong, J., Geller, M. A., and Wang, L.: Source spectra information derived from U.S. high-resolution radiosonde data, J. Geophys. Res., 113, D10106, doi:10.1029/2007JD009252, 2008.

Hoffmann, L., Xue, X. and Alexander, M. J.: A global view of stratospheric gravity wave hotspots located with Atmospheric Infrared Sounder observations, J. Geophys. Res. Atmos., 118, 416434, doi:10.1029/2012JD018658, 2013.

Huang, C. M., Zhang, S. D., and Yi, F.: Intensive radiosonde observations of the diurnal tide and planetary waves in the lower atmosphere over Yichang $\left(111^{\circ} 18^{\prime} \mathrm{E}, 30^{\circ} 42^{\prime} \mathrm{N}\right)$, China, Ann. Geophys., 27, 1079-1095, doi:10.5194/angeo-27-1079-2009, 2009.

Kuo, F. S., Lue, H. Y., Fern, C. L., Röttger, J., Fukao, S., and Yamamoto, M.: Statistical characteristics of AGW wave packet propagation in the lower atmosphere observed by the MU radar,
Ann. Geophys., 27, 3737-3753, doi:10.5194/angeo-27-37372009, 2009.

Lane, T. P., Reeder, M. J., Morton, B. R. and Clark, T. L.: Observations and numerical modeling of mountain waves over the Southern Alps of New Zealand, Q. J. R. Meteorol. Soc., 126, 27652788, doi:10.1002/qj.49712656909, 1999.

Leena, P. P., Venkat Ratnam, M., and Krishna Murthy, B. V.: Inertia gravity wave characteristics and associated fluxes observed using five years of radiosonde measurements over a tropical station, J. Atmos.-Sol. Terr. Phys., 84-85, 37-44, 2012a.

Leena, P. P., Venkat Ratnam, M., Krishna Murthy, B. V., and Vijaya Bhaskara Rao, S.: Detection of high frequency gravity waves using high resolution radiosonde observations, J. Atmos.-Sol. Terr. Phys., 77, 254-259, 2012b.

McDonald, A. J., Tan, B., and Chu, X.: Role of gravity waves in the spatial and temporal variability of stratospheric temperature measured by COSMIC/FORMOSAT3 and Rayleigh lidar observations, J. Geophys. Res., 115, D19128, doi:10.1029/2009JD013658, 2010.

Nakamura, T., Tsuda, T., Yamamoto, M., Fukao, S., and Sato, K.: Characteristics of gravity waves in the mesosphere observed with the middle and upper atmosphere radar 1. Momentum flux, J. Geophys. Res., 98, 8899-8910, 1993.

Niranjan Kumar, K., Ramkumar, T. K., and Krishnaiah, M.: Analysis of large-amplitude stratospheric mountain wave event observed from the AIRS and MLS sounders over the western Himalayan region, J. Geophys. Res., 117, D22102, doi:10.1029/2011JD017410, 2012.

Pfenninger, W. M., Liu, A. Z., Papen, G. C., and Gardner, C. S.: Gravity wave characteristics in the lower atmosphere at South Pole, J. Geophys. Res., 104, 5963-5984, 1999.

Preusse, P., Ern, M., Eckermann, S. D., Warner, C. D., Picard, R. H., Knieling, P., Krebsbach, M., Russell III, J. M., Mlynczakg, M. G., Mertensg, C. J., and Riesea, M.: Tropopause to mesopause gravity waves in August: Measurement and modeling, J. Atmos.Sol. Terr. Phys., 68, 1730-1751, 2006.

Reeder, M. J., Adams, N., and Lane, T. P.: Radiosonde observations of partially trapped Lee waves over Tasmania, Australia, J. Geophys. Res., 104, 16719-16727, doi:10.1029/1999JD900038, 1999.

Venkat Ratnam, M., Narendra Babu, A., Jagannadha Rao, V. V. M., Vijaya Bhaskar Rao, S., and Narayana Rao, D.: MST radar and radiosonde observations of inertia-gravity wave climatology over tropical stations: Source mechanisms, J. Geophys. Res., 113, D07109, doi:10.1029/2007JD008986, 2008.

Vincent, R. A. and Alexander, M. J.: Gravity waves in the tropical lower stratosphere: An observational study of seasonal and interannual variability, J. Geophys. Res., 105, 17971-17982, 2000.

Wang, D. Y. and Fritts, D. C.: Mesospheric momentum fluxes observed by the MST radar at Poker Flat, Alaska, J. Atmos. Sci., 47, 1511-1521, 1990.

Wang, L. and Alexander, M. J.: Global estimates of gravity wave parameters from GPS radio occultation temperature data, J. Geophys. Res., 115, D21122, doi:10.1029/2010JD013860, 2010.

Wang, L. and Geller, M. A.: Morphology of gravity-wave energy as observed from 4 years (1998-2001) of high vertical resolution U.S. radiosonde data, J. Geophys. Res., 108, 4489, doi:10.1029/2002JD002786, 2003. 
Wang, L., Geller, M. A., and Alexander, M. J.: Spatial and temporal variations of gravity wave parameters. Part I: Intrinsic frequency, wavelength, and vertical propagation direction, J. Atmos. Sci., 62, 125-142, 2005.

Zhang, S. D. and Yi, F.: A statistical study of gravity waves from radiosonde observations at Wuhan $\left(30^{\circ} \mathrm{N}, 114^{\circ} \mathrm{E}\right)$, China. Ann., Geophys., 23, 665-673, 2005.

Zhang, S. D. and Yi, F.: Latitudinal and seasonal variations of inertial gravity wave activity in the lower atmosphere over central China, J. Geophys. Res., 112, D05109, doi:10.1029/2006JD007487, 2007.
Zhang, S. D., Yi, F., Huang, C. M., and Zhou, Q.: Latitudinal and seasonal variations of lower atmospheric inertial gravity wave energy revealed by US radiosonde data, Ann. Geophys., 28, 1065-1074, doi:10.5194/angeo-28-1065-2010, 2010.

Zhang, S. D., Yi, F., Huang C. M., and Huang, K. M.: High vertical resolution analyses of gravity waves and turbulence at a mid-latitude station, J. Geophys. Res., 117, D02103, doi:10.1029/2011JD016587, 2012.

Zhang, S. D., Yi, F., Huang, C. M., Huang, K. M., Gong, Y., Gan, Q., and Zhang, Y. H.: Latitudinal and altitudinal variability of lower atmospheric inertial gravity waves revealed by U.S. radiosonde data, J. Geophys. Res. Atmos., 118, doi:10.1002/jgrd.50623, 2013. 